\title{
Modelagem de processos de negócios na implementação de ERPs nacionais em PMEs
}

\author{
Fernanda Pereira Carneiro da Silva \\ Néocles Alves Pereira \\ UFSCar
}

\begin{abstract}
Resumo
Este artigo apresenta evidências encontradas em uma pesquisa que teve como objetivo investigar a contribuição do uso da Modelagem dos Processos dos Negócios (MPN) na implementação do Enterprise Resource Planning (ERP) em pequenas e médias empresas (PMEs). Foi observado, nos principais fornecedores nacionais deste sistema, o uso da MPN, verificando sua influência na integração dos processos internos dos negócios de seus clientes. Para esta investigação buscaram-se as informações nos fornecedores nacionais de sistema ERP e seus clientes, mediante questionários específicos. Esta pesquisa possibilitou obter informações reais das principais características de implementação nas PMEs, destacando-se como a MPN contribui efetivamente na implementação para otimizar a integração dos processos internos dos negócios.
\end{abstract}

Palavras-chave

Enterprise Resource Planning (ERP), Sistema de Gestão Empresarial (SGE), Modelagem de Processos de Negócios (MPN) e Pequenas e Médias Empresas (PMEs).

\section{Business processes modeling in the implementation of national ERPs within SMEs}

\begin{abstract}
This article presents evidences found in a research whose objective was to investigate the contribution of using business processes modeling (BPM) in the implementation of Enterprise Resource Planning (ERP) in small and middle companies [SMEs]. The use of the BPM and assessment of its influence for the integration of the internal business processes of their customers, was also observed in the main national ERP system suppliers. To carry out this research, information was obtained by means of specific questionnaires answered by the national ERP system suppliers and their customers. This research allowed to obtain actual data about the main implementation characteristics within the SMEs, showing how the BPM effectively contributes for the implementation and better integration of the internal business processes.
\end{abstract}

Key words

Enterprise Resource Planning (ERP), Business Process Modeling (BPM], Small and Middle Enterprise [SME). 


\section{INTRODUĈ̣̃O}

Na implementação do sistema Enterprise Resource Planning (ERP), o gerenciamento dos processos de negócio, ou seja, a maneira pela qual se desenvolvem as atividades em uma organização, está sujeita a uma alteração radical. A condição essencial para que haja integração do processo de negócio é visualizar a empresa como um todo e assim quebrar as barreiras organizacionais e adquirir um entendimento de organização por processos, e não somente, por sua hierarquia funcional.

Em sistemas complexos, como são os de uma empresa, seus processos de negócios, seus componentes e suas interações estão em constante mudança, não sendo possível estabelecê-los em definitivo. Sendo, também, o ERP um sistema complexo, visto que representa os principais processos do negócio que ocorre em uma empresa, a adoção de ferramentas e metodologias de implementação pode ajudar na adequação deste sistema ao negócio do cliente, tanto na implementação quanto na melhoria do sistema ao longo de sua utilização. Podendo, ainda, estas ferramentas e metodologias ser avaliadas nos cálculos de TCO (custo total de propriedade), que leva em consideração o custo do sistema como um todo, incluindo tanto o hardware quanto os softwares utilizados e mão-de-obra para implementá-lo e assim por diante. de MPN são necessários para melhor operar e controlar os sistemas complexos.

Este artigo apresenta evidências encontradas da análise de campo de uma pesquisa que teve como objetivo investigar a contribuição do uso da MPN na implementação do ERP em pequenas e médias empresas (PMEs), observando os principais fornecedores nacionais de sistema ERP e verificando a influência deste sistema na integração dos processos internos do negócio de seus clientes usuários.

\section{A IMPLEMENTAC̣̃̃O DO ERP EM PMEs E A MPN}

Pode-se dizer que, com os avanços da TI e da comunicação, as pequenas e médias empresas (PMEs) têm condições de atender mercados distantes, formar parcerias comerciais com fornecedores e grandes clientes, como acontece em grandes empresas com seus sistemas corporativos mais robustos. Segundo Rattner (1985), a pequena empresa não representa ou reproduz as características de uma grande empresa, e a passagem de uma dimensão para outra (de pequena para média ou grande) implica mais em mudanças qualitativas do que quantitativas na estrutura da empresa. Sendo assim, ao implementar um sistema ERP em PMEs é importante considerar e representar em seus processos de negócio os aspectos qualitativos o mais fielmente possível.

Por outro lado, o estudo de PMEs tem sua relevância, pois, segundo pesquisa da IDG (2003), representam $99 \%$ das empresas no Brasil e consomem $50 \%$ do mercado de TI. Outra informação relevante é que a inclusão digital das pequenas empresas subiu de $19 \%$ para $47 \%$ e a das médias chega a $61 \%$ e que o uso de softwares integrados está entre $10 \%$ a 15\%, segundo pesquisa da Fiesp (2004).

O mercado de PMEs no Brasil é pouco

O problema do fornecedor do sistema ERP está na complexidade de implementá-lo e fazer com que se alinhe ao negócio do cliente, e por isso adota certos procedimentos ou ferramentas para facilitar este alinhamento. Para os clientes do sistema ERP, o problema está na forma de gerenciar os novos processos implementados de forma a obter resultados satisfatórios ao negócio.

Para integrar o processo de negócio, seja na busca do alinhamento do sistema ao negócio, seja para o gerenciamento adequado após a implementação, é necessário integrar completamente a empresa, compartilhando e coordenando o conhecimento. A modelagem de processos de negócio (MPN) é essencial para ajustar as lacunas entre o sistema ERP e o modelo de negócio da empresa quando se deseja o alinhamento de seus principais processos de negócio ao sistema. Para Vernadat (1996), os métodos e ferramentas explorado e predisposto a adotar sistemas como o ERP, que estão acumulados de conhecimentos adquiridos em grandes empresas e que merecem estudos em PMEs por estas empregarem práticas diferenciadas na implementação de seus sistemas, devido às suas características particulares como: tipo de negócio, dispersão geográfica, recursos financeiros. Com relação aos sistemas implementados, uma pesquisa realizada pela Microsoft Business Solution na revista Computerworld (2003) indica que o mercado de PMEs no País é estimado em cerca de 4,2 milhões de empresas, onde:

- 2,4 milhões de empresas têm ao menos um personal computer (PC);

- 400 mil PMEs utilizam algum tipo de aplicação de gestão;

- 200 mil têm um ERP implementado e, destas, apenas 100 mil são atendidas, hoje, pelos melhores fornecedores do mercado. 
Quanto ao uso de MPN na implementação, tem-se a vantagem, segundo Vernadat (1996), de configurar o sistema com as facilidades de mensurar os processos, viabilizar a melhoria contínua e de tempos entre eles, a comunicação entre o negócio e a TI utilizada, contribuição da cultura, visão da empresa, formalização de memória e maior controle das operações. Com estas facilidades oferecidas, a MPN tem o propósito de alinhar o sistema ERP à empresa, configurando suas lacunas não satisfeitas pelo sistema, e permitir criar modelos que facilitam o entendimento do que acontece na empresa e, com isto, melhorar os processos de negócio existentes ou mesmo criar novos processos ao longo do ciclo de vida do sistema ERP. Em se tratando de um sistema ERP, sua implementação, segundo SOUZA; ZWICKER (2000), não ocorre somente na fase inicial, mas também nas " $n$ " fases da utilização do sistema, ou seja, quando há necessidades de melhoria ou mesmo de novos processos. MPN é um tema que, segundo DAVENPORT (2005), deve ser a nova onda para as empresas.

\section{CARACTERIZAC̣̃̃O DA PESQUISA DE CAMPO}

Esta pesquisa foi realizada no primeiro semestre de 2004 por meio de uma Survey do tipo intencional, buscando informações nos maiores fornecedores nacionais de sistema ERP e em alguns de seus clientes. Foram aplicados dois tipos de questionários: um para os fornecedores de sistemas ERP e outro para os seus clientes usuários. Os temas abordados nos questionários estão resumidos no Quadro 1 e mais detalhes poderão ser encontrados em Silva (2005).

As análises dos questionários retornados tiveram abordagens quantitativas e qualitativas e seguiram três fases: na primeira fase foram investigados o uso de MPN nos principais fornecedores nacionais de ERP e suas características de implementação. Para a segunda fase foram selecionados dois destes fornecedores (chamados de fornecedor A e fornecedor B), líderes do mercado nacional. Na terceira fase da coleta, alguns clientes destes dois fornecedores foram analisados no sentido de verificar a influência na integração de seus processos com o ERP implementado, segundo as características de implementação de cada fornecedor.

\section{RESULTADOS ENCONTRADOS}

Com relação às respostas obtidas dos clientes, cabe observar que a maior parte foi constituída de média empresa do setor da indústria. $\mathrm{O}$ cargo ocupado pelos profissionais das empresas usuárias que responderam aos questionários ficou representado pela área de informática (77\%) e não pela área administrativa, mostrando que o sistema ERP, também nas PMEs, é administrado com o foco na tecnologia e não no negócio da empresa. Quanto ao tempo de implementação do sistema, na maioria das empresas da amostra ocorreu em até um ano.

Da sistematização dos questionários coletados foram encontradas evidências tanto para fornecedores como para clientes. Estas evidências estão reunidas no Quadro 2.

A seguir serão explicadas as origens destas evidências nas respostas dos questionários pelos fornecedores e clientes analisados.

\section{A MODELAGEM DO PROCESSO DE NEGÓCIO PELO LADO DOS FORNECEDORES}

Na Figura1 estão ilustradas a evidência 1, quanto ao uso de ferramenta computacional de MPN, e a evidência 2, referente à forma de implementação. $\mathrm{O}$ fornecedor $\mathrm{A}$, que é um dos líderes de mercado, declarou não utilizar ferramenta computacional de MPN.

Quadro 1: Resumo dos temas das questões do questionário de fornecedores e de clientes.

\begin{tabular}{|c|c|}
\hline QUESTÕES PARA OS FORNECEDORES & QUESTÕES PARA OS GLIENTES \\
\hline Questão 1 - Fatores críticos de sucesso & Questão 1 - Integração dos processos internos do negócio. \\
\hline Questão 2 - Etapas de implementação & $\begin{array}{l}\text { Questão } 2 \text { - Consideração técnica de informática e/ou de } \\
\text { negócio na implementação do sistema ERP. }\end{array}$ \\
\hline Questão 3 - Sobre a MPN & $\begin{array}{l}\text { Questão } 3 \text { - Modelagem de processos de negócios na } \\
\text { implementação. }\end{array}$ \\
\hline Questão 4 - Sobre a metodologia de implementação & \multirow{3}{*}{ Questão 4 - Customização e ferramentas na implementação. } \\
\hline Questão 5 - Alinhamento dos processos e o ERP. & \\
\hline Questão 6 - Importância da Modelagem & \\
\hline
\end{tabular}

Fonte: SILVA, 2005. 
Os fornecedores B e C oferecem a mesma solução ERP ao mercado e declararam utilizar diferentes ferramentas de MPN na implementação. Por pertencerem à mesma empresa matriz da solução ERP, perde-se a oportunidade de se adotar uma ferramenta padronizada de MPN para que pudessem, com as experiências de cada implementação em clientes de outras regiões, compartilhar diversos modelos de referência (MR) que surgissem no decorrer destas modelagens nas várias implementações.

Para a evidência 3, relativa às características da ferramenta de modelagem, considerou-se, no Quadro 3, um conjunto de características que os fornecedores aderiram empregar ao utilizar procedimentos de MPN.

Destas características, $\mathrm{C} 1$ e C4 foram as mais assinaladas pelos fornecedores, indicando que os processos são traduzidos para símbolos de modo a facilitar o entendimento comum, amenizando a complexidade do gerenciamento empresarial.

A característica $\mathrm{C} 2$ foi a menos assinalada e diz respeito a ter visões diferenciadas do negócio, mostrando que para os fornecedores vale mais ter uma visão acurada e de fácil leitura da empresa do que ter várias visões do negócio da empresa.

A evidência 4, sobre utilização de modelos de referência (MR), teve origem nas informações das respostas dadas por todos os fornecedores em uma questão aberta, cujo tema referia-se ao alinhamento dos processos de negócio do cliente ao ERP quando o mesmo não possui a "melhor prática" do processo.

Como o ERP é um sistema de solução genérica, é comum, seja pelo custo ou por sua complexidade, ficarem impraticáveis grandes modificações para o alinhamento de processos ofereci-

Quadro 2: Evidências encontradas nas análises dos questionários de fornecedores e clientes.

\begin{tabular}{|c|c|}
\hline \multicolumn{2}{|r|}{ DESCRIÇÃO DA EVIDÊNCIA } \\
\hline Evidência 1 - F & $\begin{array}{l}\text { A ferramenta computacional de MPN parece não ser, ainda, um diferencial entre as fornecedoras } \\
\text { de sistema ERP, visto que um dos fornecedores líder de mercado não a utiliza. }\end{array}$ \\
\hline Evidência 2 - F & $\begin{array}{l}\text { A forma de implementação de fornecedores franquiados do mesmo sistema ERP não } \\
\text { necessariamente é a mesma. }\end{array}$ \\
\hline Evidência 3 - F & $\begin{array}{l}\text { A maioria das características da ferramenta de MPN está presente nos procedimentos dos } \\
\text { fornecedores. }\end{array}$ \\
\hline Evidência 4 - F & Por volta de metade dos fornecedores indicou utilizar modelos de referência na implementação. \\
\hline Evidência 5 - F & $\begin{array}{l}\text { O uso de MPN facilita a implementação, permite criar modelos, contribui no treinamento e na } \\
\text { construção de novos processos. }\end{array}$ \\
\hline Evidência 6 - F & $\begin{array}{l}\text { O fornecedor } A^{*} \text {, que não utiliza ferramenta computacional de suporte na implementação, } \\
\text { considera um maior número de etapas de implementação do que o fornecedor } B^{*} \text { que utiliza. }\end{array}$ \\
\hline Evidência 7 - F & $\begin{array}{l}\text { As características básicas para que ocorra uma boa MPN não constaram no fornecedor que } \\
\text { utiliza a ferramenta computacional. }\end{array}$ \\
\hline Evidência 8 - C & $\begin{array}{l}\text { Os clientes que optaram por fazer a MPN, independentemente do fornecedor, conseguiram as } \\
\text { maiores porcentagens de integração em seus processos. }\end{array}$ \\
\hline Evidência 9 - C & A maior porcentagem de integração dos processos ocorreu no setor da indústria e não de serviço. \\
\hline Evidência 10 - C & $\begin{array}{l}\text { O principal motivo dos clientes em não fazer a MPN foi à aceitação direta das "melhores } \\
\text { práticas" embutidas no ERP. }\end{array}$ \\
\hline Evidência 11 - C & $\begin{array}{l}\text { Para a implementação do sistema ERP, os clientes que optaram em fazer a MPN, } \\
\text { independentemente do fornecedor, resultaram nos maiores valores de porcentagens dos } \\
\text { aspectos de negócio e técnico. }\end{array}$ \\
\hline Evidência 12 - C & $\begin{array}{l}\text { Em implementações de menos de um ano, os valores percentuais do aspecto técnico na } \\
\text { implementação só ocorreu em clientes que optaram em fazer a MPN. }\end{array}$ \\
\hline 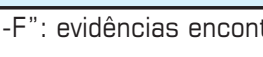 & adas nas respostas dos fornecedores; \\
\hline & das lids Tespustas uus lilentes. \\
\hline & ticipantes da segunda fase da coleta e cujos clientes foram analisados. \\
\hline ILVA, 2005). & \\
\hline
\end{tabular}


dos pelo sistema ao negócio a ser implementado. Portanto, muitas vezes, os fornecedores oferecem MR que já possuem uma solução inicial de sistema com processos de negócio específicos de um determinado setor. Partindo deste conceito de MR, as modificações de alinhamento ficam em menor proporção de custo, tempo e de complexidade para o cliente.

Vale lembrar que a ferramenta de MPN pode validar ou não um MR, pois poderá com ela levantar e modelar os processos antes de implementá-lo, tornando-a de muita utilidade para uma tomada de decisão de implementação sobre um determinado MR. Segundo Vernadat (1996), as vantagens de se adotar um MR consistem em:

- redução de tempo/custo no desenvolvimento de um modelo particular;
- comparação das atividades (melhores práticas) da empresa com a proposta pelo modelo;

- melhor suporte na implementação.

Com isto posto, algumas observações foram feitas com base em trechos de respostas para esta questão, indicando a utilização ou não de um MR e das facilidades que estão oferecendo para este caminho.

Percebe-se, na Tabela 1, que os fornecedores A, C e D não indicam o uso de algum $\mathrm{MR}$ em suas respostas. Pelo fato de os fornecedores C e D citarem a utilização da ferramenta computacional de MPN (ver Figura 1), era de se esperar que oferecessem algum MR, ou algo similar, ou ainda propusessem a construção de um MR para o alinhamento mais

Figura 1: Uso da ferramenta computacional de MPN na implementação.

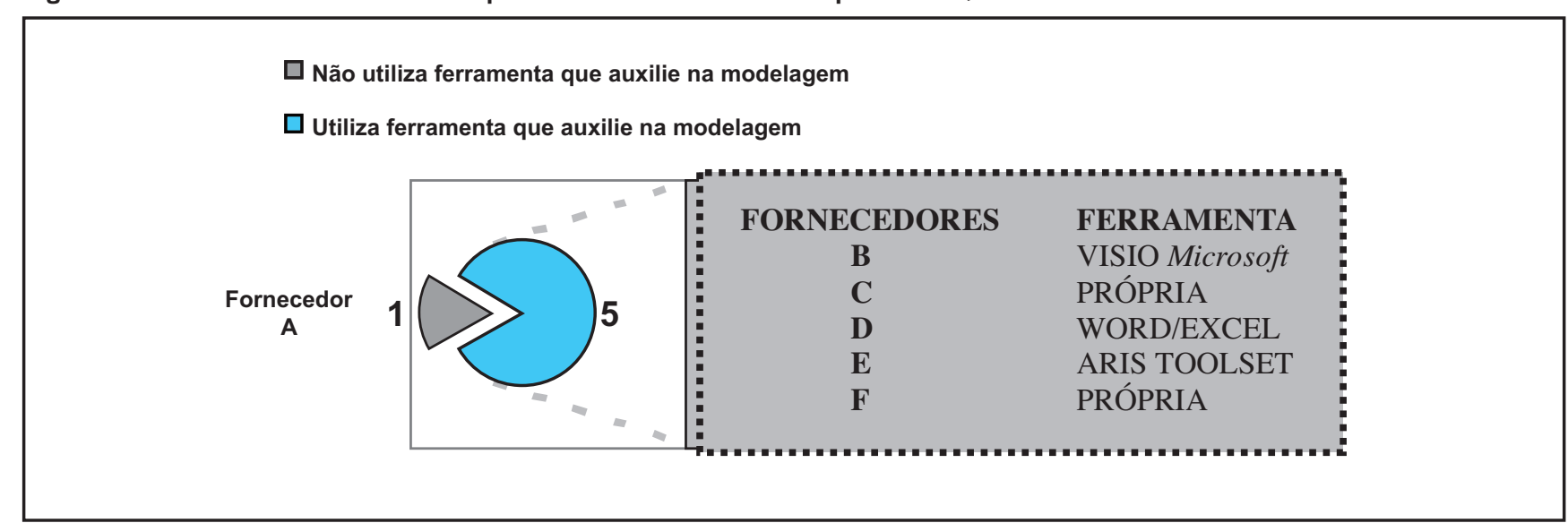

Fonte: (SILVA, 2005).

Quadro 3: Características consideradas pelo fornecedor ao utilizar procedimentos de MPN.

\begin{tabular}{|l|l|}
\hline C1 & Capturar, exteriorizar, formalizar os processos empresariais. \\
\hline C2 & Gerar diferentes visões do negócio. \\
\hline C3 & Decomposição funcional (mapeamento das funções do macro ao micro) \\
\hline C4 & Definição do modelo dos processos por módulos. \\
\hline C5 & Generalização (possibilita a criação de classes que agrupem em objetos) \\
\hline G6 & Aproveita parte do modelo construído em outro novo modelo. \\
\hline C7 & O modelo gerado é dinâmico (tipo simulação). \\
\hline C9 & O modelo gerado é estático. \\
\hline C10 & Separação entre atividades e recursos \\
\hline C11 & Conformidade (acurácia na representação). \\
\hline C12 & Simplicidade e adequação. \\
\hline C13 & Gerencia a complexidade e o dinamismo empresarial. \\
\hline
\end{tabular}

C(1...13): Características dos procedimentos com MPN.

Fonte: (SILVA, 2005). 
próximo ao negócio do cliente, isto pode indicar um uso limitado da ferramenta.

A evidência 5, relativa ao uso de MPN, tem como base as respostas dos fornecedores na questão referente à importância de um cliente ter os seus processos de negócio modelados na visão dos fornecedores.
1 e 2 do questionário de fornecedores. As opções para cada aspecto foram retiradas de Umble et al. (2002) apud SILVA (2005, p. 51).

Observa-se no Quadro 4 que os fatores críticos de sucesso são menos considerados nas pequenas empresas, de ambos os fornecedores, do que nas médias empresas. Merecendo destaque o treinamento adequado (FCS 9) que ambos os fornecedores concordaram ser importante tanto para a pequena quanto para a média empresa.

Um aspecto que chama atenção no Quadro 4 é o fato de o fornecedor A não adotar um grupo de implementação (FCS 8) apesar de indicar o gerenciamento adequado do projeto (FCS 2) como relevante.

Quanto à consideração de a medição

Algumas constatações dos benefícios da MPN na implementação puderam ser destacadas dos trechos das respostas destes fornecedores, como: facilitar a implementação (fornecedor A), criar modelos (fornecedor B), treinar em novos processos (fornecedor $\mathrm{D}$ ), direcionar a implementação (fornecedor E) e para compartilhar com os clientes as definições dos processos do negócio (fornecedor F). Apenas o fornecedor B declara não ser imprescindível o uso da MPN na implementação do cliente.

Comentando a resposta do fornecedor B, o fato de criar modelos e ajustar-se à realidade do cliente mostra uma maturidade em desenvolver a solução e uma evidência de que existem modelos de referência em suas implementações.

As evidências 6 e 7 são baseadas nas respostas dos fornecedores A e B, que foram selecionados para a segunda fase da pesquisa e que tiveram seus clientes analisados na terceira fase. Para a evidência 6, referente às etapas de implementação consideradas pelos fornecedores, o Quadro 4 sintetiza os retornos dos fornecedores $\mathrm{A}$ e $\mathrm{B}$ quanto à importância dos Fatores Críticos de Sucesso e das Etapas de Implementação utilizadas em suas implementações. Estes dois aspectos correspondem, respectivamente, às questões de desempenho (FCS 5) não ter sido marcada, vale comentar a importância deste fato para o cliente quando uma solução ERP está sendo implementada, no sentido de ter o controle das atividades. Este acompanhamento poderia estar atrelado ao fluxo de pagamento do cliente ao seu fornecedor.

Quanto às etapas de implementação, na parte inferior do Quadro 4, nota-se que o fornecedor A dá praticamente a mesma atenção para a pequena empresa como para a média empresa.

Quanto à etapa 4 não ter sido marcada, um possível motivo é que pode haver outros modos de treinamento sendo utilizados que não por software de treinamento para os iniciantes do sistema, visto que o item treinamento adequado (FCS 9) foi unânime na marcação dos fornecedores.

Por último, tanto a etapa 1 como a etapa 9 foi marcada por ambos os fornecedores em ambos os casos (pequena e média empresa). Em particular, a etapa 1 ser marcada pelo fornecedor A causa estranheza pelo fato de não usar a ferramenta de MPN, podendo ser, portanto, fonte de dificuldade na implementação e na qualidade da aderência resultante.

Para melhor entendimento da evidência 7 , referente às características básicas para que ocorra uma boa MPN, no

Tabela 1: Indicações de utilização de modelos de referência e facilidades para o alinhamento do ERP ao cliente.

\begin{tabular}{|l|l|l|}
\hline & INDICA MR & \multicolumn{1}{c|}{ FACILIDADES } \\
\hline Fornecedor A & Não & Ensinar / Treinamento \\
\hline Fornecedor B & Sim & Modelos / Base pré-parametrizada \\
\hline Fornecedor C & Não & Ensinar \\
\hline Fornecedor D & Não & - \\
\hline Fornecedor E & Sim & Recomendações / Sugestões/Análise de aderência \\
\hline Fornecedor F & Sim & Experiências anteriores em construir modelos \\
\hline
\end{tabular}


Quadro 5 são reproduzidas as características de MPN que são atendidas, ou não, nos procedimentos de implementação utilizados nos dois fornecedores, A e B.

Observa-se no Quadro 4 que onze das treze características são consideradas por ao menos um fornecedor, mostrando a importância da MPN nas implementações de PMEs.

Analisando sob a ótica do fornecedor A, lembrando que este não utiliza ferramenta computacional para fazer a MPN, a marcação da característica C7 é conflitante, pois diz que sua ferramenta de MPN, gera um modelo dinâmico que possibilita simulações de modelos. Como pode obter um modelo dinâmico sem o uso de ferramenta computacional para a MPN sem utilizar a ferramenta computacional da
MPN? Neste caso deveria ter marcado a C8, que seria a mais condizente com sua realidade.

$\mathrm{O}$ fornecedor $\mathrm{A}$ não marcou a $\mathrm{C} 11$, que diz respeito a ter uma boa visualização para leitura e representação do modelo, ao contrário do fornecedor $\mathrm{B}$ que a marcou, ou seja, isto pode ser decorrente de utilização da forma ambígua das técnicas de modelagem que pode ser simples, mas tem que garantir adequação ao propósito do modelo.

Nota-se uma diferença na MPN feita pelo fornecedor A em relação ao fornecedor $\mathrm{B}$, o que é identificado pela marcação de três características C3, C4 e C11. Estas características têm uma relação lógica de dependência, ou seja, com a C3 é percebido que o fornecedor A faz a MPN mapeando as

Quadro 4: Comparação de FCS e Etapas de implementação dos fornecedores A e B.

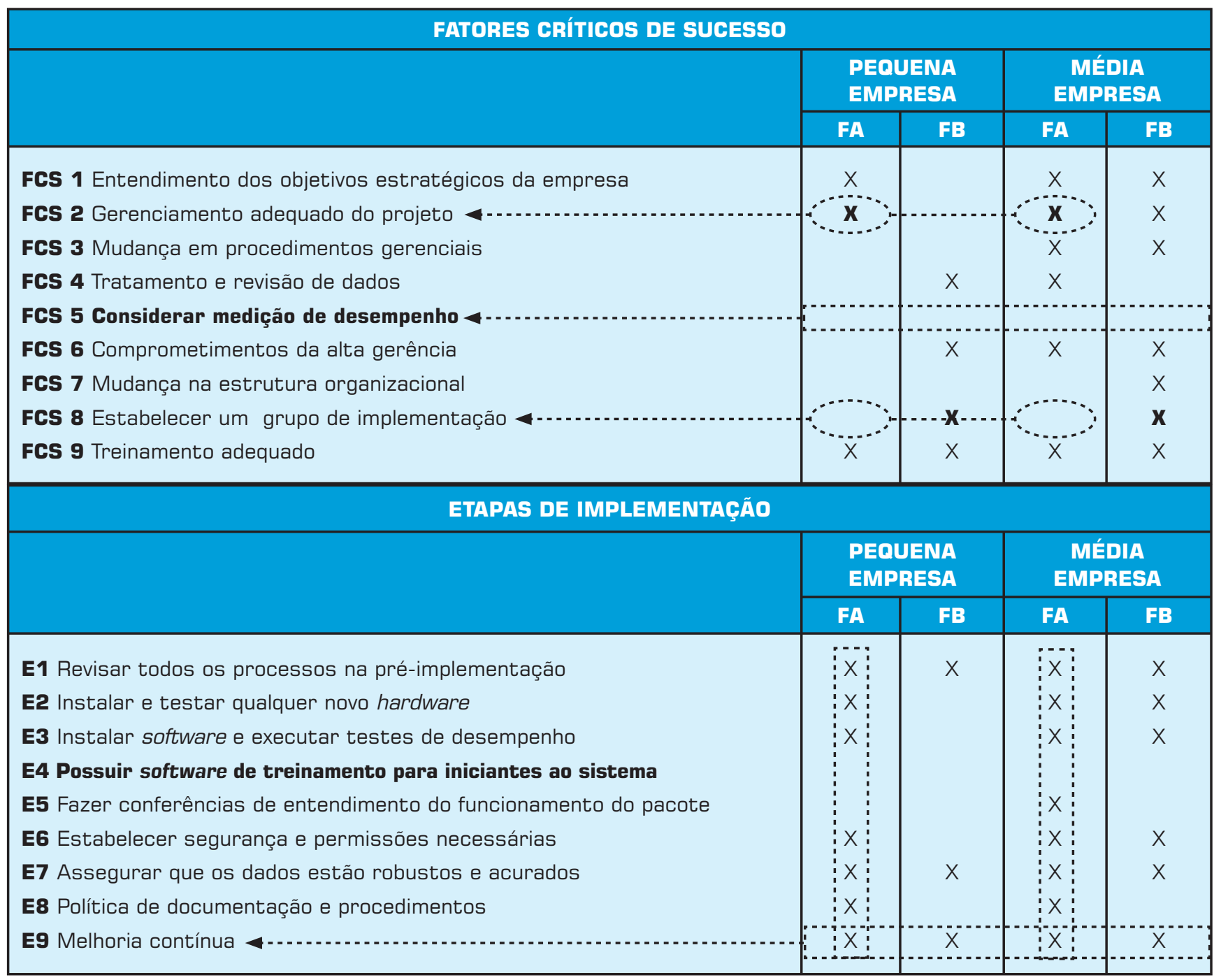

FA - fornecedor A; FB - fornecedor B; E(1...9): etapas de implementação; FCS: Fator Crítico de Sucesso.

Fonte: (SILVA, 2005). 
funções hierárquicas (chamadas de macrofunções) e depois as decompõe em funções mais específicas (chamadas de microfunções), ou seja, transcreve-se de forma clara a estrutura organizacional a que se está desenhando, pois este link de macrofunção com a microfunção é muito importante para se obter um fluxo "limpo" de informações do processo. A importância da C4, marcada por ambos, está no engajamento do modelo gerado aos módulos do sistema para que ocorra um efetivo alinhamento do negócio ao sistema. Estas duas características, quando consideradas, facilitam a $\mathrm{C} 13$, que é referente ao gerenciamento da complexidade e do dinamismo da empresa, que não foi marcada pelo fornecedor $\mathrm{B}$, fazendo com que o fluxo de informações da organização seja captado pelo modelo e, assim, permitindo uma melhor aderência dos processos da empresa aos módulos oferecidos pelo sistema.

\section{AS EVIDÊNCIAS PELO LADO DOS CLIENTES}

Para as evidências 8 e 9, referentes respectivamente à opção de se fazer a MPN e à porcentagem de integração dos processos, será utilizada a Tabela 2 que mostra o cruzamento de questões cujos temas abordavam a porcentagem de integração nos processos de negócio do cliente e a opção do cliente pelo uso de MPN na implementação. Esta tabela foi ordenada pelos clientes que fizeram, ou não, a MPN, gerando dois grupos (ver coluna "Houve modelagem").

Uma primeira observação a ser feita é que a porcentagem de integração dos processos dos clientes que optaram por fazer a MPN é maior. Esta porcentagem de integração foi obtida pela somatória das marcações dos itens da questão 1 (questionário de clientes), referente à integração dos processos internos do negócio, com abordagens de como interagem as informações entre as áreas, se há compreensão quanto às entradas e saídas do sistema, se há ações de melhoria dos processos utilizados e se os usuários participam destas ações, etc.

Algumas possíveis tendências podem ser observadas na Tabela 2 com relação à integração dos processos. A média do percentual de integração dos processos para as empresas que utilizaram a MPN é maior do que a média das empresas que não utilizaram: $72 \%$ contra $48 \%$. Além disso, a variabilidade do percentual de integração é menor, ou seja, melhor, para as que usaram MPN.

Outra constatação é que a média do percentual de integração dos processos entre as indústrias é maior do que nas empresas de serviço: $61 \%$ contra $56 \%$. A variabilidade do percentual também é melhor para as indústrias, ou seja, é menor do que nas empresas de serviço. Davenport (1998) indica que em empresas de serviços há maior dificuldade na implementação de uma solução ERP.

Estas duas tendências, acima, permanecem mesmo quando se considera separadamente a situação de empresas industriais e de serviços que usaram ou não MPN.

Por último, ainda na Tabela 2, considerando agora o porte das empresas, a média do percentual de integração dos processos é mais favorável para as pequenas empresas do que para as médias empresas: $64 \%$ contra $56 \%$. Na mesma direção, a variabilidade também é bem mais favorável para as pequenas empresas: um desvio padrão de $9 \%$ para

\section{Quadro 5: Características da MPN nos procedimentos adotados.}

\begin{tabular}{|c|l|c|c|}
\hline \multicolumn{1}{|c|}{ CARACTERÍSTICAS DA MPN } & FA & FB \\
\hline C1 & Capturar, exteriorizar, formalizar os processos empresariais. & SIM & SIM \\
\hline C2 & Gerar diferentes visões do negócio. & NÃO & NÃO \\
\hline C3 & Decomposição funcional (mapeamento das funções do macro ao micro). & SIM & NÃO \\
\hline C4 & Definição do modelo dos processos por módulos. & SIM & SIM \\
\hline C5 & Generalização (possibilita a criação de classes que agrupem em objetos). & NÃO & NÃO \\
\hline C6 & Aproveita parte do modelo construído em outro novo modelo. & SIM & SIM \\
\hline C7 & O modelo é dinâmico (tipo simulação). & SIM & SIM \\
\hline C8 & O modelo é estático. & NÃO & SIM \\
\hline C9 & Separação entre atividades e recursos. & SIM & SIM \\
\hline C10 & Conformidade (acurácia na representação). & SIM & SIM \\
\hline C11 & Visualização (fácil leitura e representação). & NÃO & SIM \\
\hline C12 & Simplicidade e adequação. & SIM & SIM \\
\hline C13 & Gerencia complexidade e o dinamismo empresarial. & SIM & I NÃO \\
\hline
\end{tabular}

C(1...13): Características da MPN.

Fonte: (SILVA, 2005). 
as pequenas empresas, contra $21 \%$ para as médias empresas. Esta situação pode ser devido a menor dificuldade de implementação de um sistema deste tipo em uma pequena empresa, devido à menor complexidade de seus negócios, se comparada com uma média empresa.

Com respeito à evidência 10 , sobre o motivo dos clientes em não fazer a MPN, a Figura 2 mostra as justificativas daqueles clientes que optaram por não fazer a MPN na implementação.

A justificativa de "aceitação das melhores práticas" foi a mais citada, indicando que o cliente acredita que o sistema ERP já traz, embutidos, os melhores processos para o seu negócio. A opção "custo" foi a segunda mais citada, mostrando ser uma outra justificativa da não utilização da MPN na implementação. Com relação ao custo, os autores Rozenfeld e Amaral (2003) dizem que a principal desvantagem na modelagem de empresas, além dos altos custos envolvidos, está na complexidade de gerar modelos que exigem a representação de diferentes tipos de elementos (informação, organização, métodos, conhecimento, etc.), com grandes e diversificadas interações entre si. Isto, também, exige um profissional especializado que saiba direcionar o planejamento destas atividades de análise, e por isso os clientes optam por não fazer a MPN.

Na evidência 11, sobre os aspectos de negócio e técnico, são mostrados na Tabela 3 os aspectos de negócio e técnicos que foram obtidos da somatória dos itens da questão 2 do questionário de clientes, encontradas em SILVA (2005, p. 173), em que a cada item da questão foi atribuído um peso para estes aspectos. Como exemplo, o primeiro item da questão 2 referia-se à marcação do cliente com uma pontuação de 0 a 2 quanto à importância de a empresa possuir missão, objetivos, estratégia. Este item possuía peso 3 para o aspecto

\section{menos de um grande fornecedor, foi - constatado que os demais fornecedores de sistema ERP considerados usam a modelagem de processos de negócios com apoio da ferramenta computacional.}

de negócio. Um outro item desta questão com peso 3, só que voltada para o aspecto técnico, referia-se à linguagem computacional utilizada pelo sistema ERP.

Segundo Davenport (2002), os aspectos de negócio e técnico são considerados na implementação do ERP que tem como influência o tempo de implementação. $\mathrm{O}$ aspecto técnico na implementação garante a boa funcionalidade do sistema e altera minimamente o processo e o aspecto de negócio permite alterações que maximizam o valor da organização e de seus processos. Outra forma de porcentagem

Tabela 2: A opção do uso da MPN pelo cliente e a integração dos processos.

\begin{tabular}{|c|c|c|c|c|}
\hline CLIENTE & PORTE & SETOR & HOUVE MODELAGEM? & \% INTEGRAÇÃo \\
\hline $\mathbf{a ( 1 )}$ & Média & indústria & Não & 55,6 \\
\hline $\mathbf{a ( 3 )}$ & Média & indústria & Não & 55,6 \\
\hline $\mathbf{a ( 7 )}$ & Média & Serviço & Não & 22,2 \\
\hline $\mathbf{a ( 8 )}$ & Média & Indústria & Não & 55,6 \\
\hline $\mathbf{a ( 1 0 )}$ & Pequena & Serviço & Não & 55,6 \\
\hline $\mathbf{b ( 1 )}$ & Pequena & Indústria & Não & 55,6 \\
\hline $\mathbf{b ( 3 )}$ & Média & Indústria & Sim & 33,3 \\
\hline $\mathbf{b ( 2 )}$ & Média & Indústria & Sim & 88,9 \\
\hline $\mathbf{a ( 5 )}$ & Pequena & Indústria & Sim & 77,8 \\
\hline $\mathbf{a ( 2 )}$ & Média & Serviço & Sim & 66,7 \\
\hline $\mathbf{a ( 4 )}$ & Média & Indústria & Sim & 66,7 \\
\hline $\mathbf{a ( 6 )}$ & Pequena & Serviço & Sim & 66,7 \\
\hline $\mathbf{a ( 9 )}$ & Pequena & Serviço & 66,7 \\
\hline
\end{tabular}

a (...): clientes do fornecedor $A$

b (...): clientes do fornecedor B.

Fonte: (SILVA, 2005). 
mostrada nesta Tabela 2 é a de integração dos processos, que foi obtida pela somatória das marcações dos itens da questão 1 (feita pelos clientes).

Observa-se na Tabela 3 que os clientes foram agrupados naqueles que usaram modelagem e naqueles que não usaram. Nota-se que os aspectos de negócio e técnico para alguns clientes, que fizeram a MPN chegou a 100\%. Ainda, para os clientes que se utilizaram de MPN, tanto a média dos percentuais para os aspectos de negócio como a média para os aspectos técnicos são melhores, se comparados com os clientes que não usaram MPN. Por exemplo, para o percentual de negócio, a média entre os clientes que usaram MPN foi de $72 \%$, enquanto que, para os que não usaram, foi de $42 \%$. Com relação ao percentual tecnológico, estas médias foram respectivamente $75 \%$ e $20 \%$.

Figura 2: Justificativas dos clientes que não fizeram a MPN.

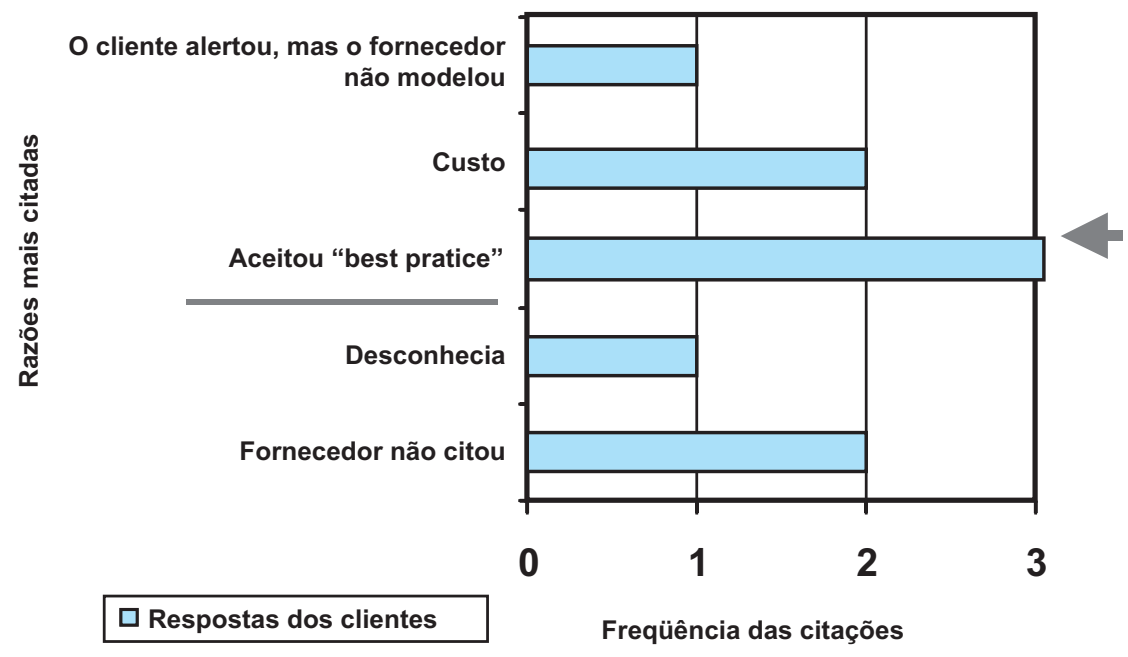

Fonte: (SILVA, 2005).

Tabela 3: Os aspectos de Negócio (N) e Técnico na implementação (T) e a influência da MPN.

\begin{tabular}{|c|c|c|c|c|c|c|}
\hline CLIIENTE & PORTE & SETOR & \% INTEGRAÇÃO & HOUVE MODELAGEM? & $\% \mathrm{~N}$ & $\% \mathrm{~T}$ \\
\hline$a(1)$ & Média & Indústria & 55,6 & Não & 67 & 8 \\
\hline$a(3)$ & Média & Indústria & 55,6 & Não & 19 & 42 \\
\hline$a(7)$ & Média & Serviço & 22,2 & Não & 50 & 25 \\
\hline$a(8)$ & Média & Indústria & 55,6 & Não & 39 & 42 \\
\hline$a(10)$ & Pequena & Serviço & 55,6 & Não & 39 & 0 \\
\hline b(1) & Pequena & Indústria & 55,6 & Não & 69 & 25 \\
\hline b(3) & Média & Indústria & 33,3 & Não & 14 & 0 \\
\hline$a(2)$ & Média & Serviço & 66,7 & Sim & - 58 & 33 \\
\hline$a(4)$ & Média & Indústria & 66,7 & Sim & 100 & 100 \\
\hline$a(5)$ & Pequena & Indústria & 77,8 & Sim & 72 & 92 \\
\hline$a(6)$ & Pequena & Serviço & 66,7 & Sim & 72 & 100 \\
\hline$a(9)$ & Pequena & Serviço & 66,7 & Sim & 58 & 100 \\
\hline$b(2)$ & Média & Indústria & 88,9 & Sim & 72 & 25 \\
\hline
\end{tabular}

Fonte: (SILVA, 2005). 
$\mathrm{Na}$ Tabela 4, algumas relações foram feitas quanto ao tempo de implementação do sistema ERP, visto que, segundo Davenport (2002), os aspectos de negócio e técnico são influenciados por este tempo.

Considerando que até um ano seja um prazo curto de implementação, é notada a tendência do aspecto técnico na implementação em todos que fizeram a MPN, chegando a 100\% em alguns clientes nas áreas pontilhadas. Nos clientes que não fizeram a MPN, isto não ocorreu, inclusive, ficando alguns com seus valores zerados, nas áreas demarcadas com retângulo. Nota-se, com isto, que o curto prazo de implementação não atingiu, em alguns clientes, nem o aspecto técnico (T) do pacote quando implementado, o que já poderia justificar o investimento num sistema ERP.

Para ilustrar a consideração acima, observa-se nas Tabelas 3 e 4 que o cliente b(3) obteve uma baixa integração de seus processos, ficando com o valor zero no aspecto técnico e a menor porcentagem de integração nos processos de negócio em relação aos outros clientes (ver Tabela 3).Por isso, neste cliente, foi realizada uma análise mais aprofundada com o intuito de checar suas respostas dadas ao questionário, principalmente no que se referia à integração dos processos de negócio da empresa em relação ao sistema ERP que utilizava.

Percebeu-se que muitos módulos do sistema não eram utilizados de forma completa, como era o caso do módu- lo de produção, onde só eram feitos os apontamentos de produção e o restante das atividades eram realizadas em planilha Excel. No final de 2004, este cliente estava em processo de implementação do BI (Business Intelligence) e da troca de dados (EDI), que eram considerados processos estratégicos para a empresa e ficaram de fora do sistema ERP.

\section{A s características mais marcantes na MPN estão na tradução dos processos em símbolos e em amenizar a complexidade} do entendimento da empresa.

Tabela 4: A influência do tempo de implementação e a relação com os aspectos de Negócio e Técnico e a opção da MPN.

\begin{tabular}{|c|c|c|c|c|c|c|}
\hline CLIENTE & $\begin{array}{c}\text { TEMPO DE } \\
\text { IMPLEMENTAÇÃO }\end{array}$ & PORTE & SETOR & $\begin{array}{c}\text { HOUVE } \\
\text { MODELAGEM? }\end{array}$ & $\% N$ & $\% \mathrm{~T}$ \\
\hline$a(1)$ & 5,8 anos & Média & indústria & Não & 67 & 8 \\
\hline$a(3)$ & 4,6 anos & Média & indústria & Não & 19 & 42 \\
\hline$a(5)$ & 1,9 ano & Pequena & indústria & Sim & 72 & 92 \\
\hline$a(2)$ & 1,6 ano & Média & Serviço & Sim & 58 & 33 \\
\hline$a(7)$ & 1,5 ano & Média & Serviço & Não & 50 & 25 \\
\hline$b(2)$ & 1,3 ano & Média & Indústria & $\operatorname{Sim}$ & 72 & 25 \\
\hline$b(1)$ & 1 ano & Pequena & Indústria & Não & 69 & 25 \\
\hline$a(4)$ & 10 meses & Média & Indústria & Sim & 100 & 100 \\
\hline $\mathrm{a}(10)$ & 7 meses & Pequena & Serviço & Não & $\overline{39}$ & 0 \\
\hline$b(3)$ & 7 meses & Média & Indústria & Não & 14 & 0 \\
\hline$a(6)$ & 6 meses & Pequena & Serviço & Sim & & 100 \\
\hline$a(9)$ & 6 meses & Pequena & Serviço & & $5 \overline{8}$ & 100 \\
\hline$a(8)$ & 4 meses & Média & Indústria & Não & $\overline{3} \overline{9}$ & 42 \\
\hline
\end{tabular}

Fonte: (SILVA, 2005). 


\section{CONCLUSÕES}

Este trabalho considerou uma pesquisa de campo junto aos principais fornecedores nacionais de ERP, bem como junto a seus clientes. Foram levantadas diversas evidências a respeito da adoção de modelagem de processos de negócios para a implementação desses sistemas e o impacto, nestas empresas clientes, com ou sem a adoção da modelagem. flow de microprocessos, diminuir impactos negativos da implementação e fazer um Road Map de implementação. Segundo estes fornecedores, a MPN facilita a implementação, permite criar modelos de referência, contribui para o treinamento e para construção de novos processos.

Este estudo mostrou que quando o cliente opta pela utilização da MPN, independentemente do fornecedor utilizar ou não ferramenta computacional, é obtido um maior percentual de integração nos seus processos internos. Em clientes que implementaram em um tempo curto (menos de um ano) a opção de fazer a MPN mostrou-se benéfica, visto que estes clientes obtiveram os mais altos percentuais de integração e garantiram altos percentuais tanto no aspecto técnico de implementação quanto no de negócio.

No cliente em que houve um aprofundamento deste estudo, se tivesse sido utilizada a MPN, haveria possibilidades de: evitar customizações desnecessárias, aproveitar conhecimento adquirido do grupo de implementação

Foi identificado que a maioria dos fornecedores de sistema ERP consultados estava usando MPN com apoio da ferramenta computacional na maioria deles. Entretanto, foi observado o uso limitado desta ferramenta quanto, por exemplo, à utilização e geração de modelos de referência na implementação e, ainda, para fornecedores que oferecem a mesma solução ERP, pela perda de oportunidade de compartilhar experiências de implementação com uma adoção padronizada da ferramenta de MPN.

As características mais marcantes na MPN destes fornecedores estão na tradução dos processos em símbolos para facilitar o entendimento comum e amenizar a complexidade do dinamismo da empresa, bem como facilitar alterações e manipulações dos modelos gerados pela modelagem. Os fornecedores que utilizam a ferramenta computacional disseram com seu uso revisar processos, elaborar work- e depois disseminá-la ao restante dos usuários.

Considerando a amostra utilizada, não se pode generalizar com esta pesquisa que sem a MPN o benefício da integração não acontece em todas as empresas.

A maior e melhor integração interna de seus negócios com o uso de MPN possibilita à empresa um amadurecimento interno do sistema ERP, pois permite uma maior facilidade de visualização e entendimento dos inter-relacionamentos dos processos internos do negócio e, com isto, possibilita um avanço do sistema ao ambiente externo de relacionamento com parceiros e clientes, tão relevante em um ambiente competitivo.

Portanto, considerar a MPN na implementação é uma forma efetiva de se compatibilizar o negócio de uma empresa ao sistema ERP, conduzindo ao gerenciamento de um processo de negócio integrado. 
- Referências Bibliográficas

BRYMAN, A. Survey Research. Research Methods and Organization Studies. Loughborough University, p. 105-134, 1988.

CAMEIRA, F. R.; CAULLIRAUX, M. H. Engenharia de Processos de Negócios: considerações metodológicas com vistas à análise e integração de processos. Grupo de Produção integrada - UFRJ - COPPE \& Poli, 2000. Disponível em: < http://www.gpi.ufri.br/pdfs/ artigos $>$. Acesso em: 10/12/2004.

DAVENPORT, T. H. Putting the Enterprise into the Enterprise System. Enterprise Systems. Harvard Business Review, Elservier Science, p. 121-131, jul./aug. 1998

DAVENPORT, T. H. Missão Crítica: obtendo vantagem competitiva com os sistemas de gestão empresarial. Trad. Raul Rubenich, Porto Alegre: Bookman, 2002.
DAVENPORT, T.H. Comoditização de Processos - a nova onda, Harvard Business Review, edição em português, p. 76-84, Jun. 2005.

FIESP/FEA-USP; Idigital - Pesquisa Perfi da Empresa Digital Resultados Completos da terceira edição (2003/2004). Disponível em: <http://www.idigital.fea.usp.br/iDigital $>$. Acesso em: 6/2004

FIESP/FIPE. Idigital - Pesquisa Perfil da Empresa Digital primeira edição. Gerência de Pesquisa e cadastro da FIESP - Federação das indústrias do Estado de São Paulo. Edição 2001/2002. Disponível em: $<$ http://www.fiesp.com.br>. Acesso em $16 / 4 / 2003$.
IDG-Now. Pequenas e médias devem investir mais em TI em 2003. ComputerWorld - Negócios. Disponível em:http://www. computerworld.com.br/AdPortalV3/. Acesso em: 17/09/2003.

RATTNER, H. Pequena Empresa: o comportamento empresarial na acumulação e na luta pela sobrevivência. Conselho Nacional de Desenvolvimento Científico e Tecnológico de Brasília. São Paulo: Brasiliense, 1985.

ROZENFELD, H.; AMARAL, C. D. Modelagem de Empresas. Grupo NUMA - Núcleo de Manufatura Aplicada da USP - São Carlos. Disponível em: <http://www. numa.org.br/conhecimentos/conhecimentos_port/pag_conhec/Modelagemv1. html>. Acesso em: 12/12/2003.
SLACK, N.; CHAMBERS, S.; JOHNSTON R; tradução OLIVEIRA, M. T. C; ALHER, F.; Administração da Produção, 2. ed. São Paulo: Atlas, 2002.

SILVA, F. P. C. da. Contribuição do Uso da Modelagem de Processos de Negócios na Implementação de ERP de Fornecedores Nacionais em Pequenas e Médias Empresas. São Carlos, 2005, 193 p Dissertação, Universidade Federal de São Carlos

VERNADAT, F. B. Enterprise Modelling and Integration: Principles and Applications. London: Chapman \& Hall, 1996.

\section{- Sobre os autores}

\section{Fernanda Pereira Carneiro da Silva}

Professora de Administração da Produção.

End.: Rua XV de Novembro, 559 ap. 52 - Centro - 13400-360.

Tel.: (19) 3432-9336

E-mail: ferpcarneiro@uol.com.br

\section{Néocles Alves Pereira}

Universidade Federal de São Carlos - UFSCar

Prof. Dr. Departamento de Engenharia de Produção

Endereço: Rodovia Washington Luis, Km 235 - 13.565-905 - São Carlos - SP

Fone: (016) 3351-8237 ramal 275

E-mail: neocles@power.ufscar.br 